\title{
Simple and Efficient Eco-Friendly Multigram Procedure for Preparation of Piperazine Hydrochloride, an Important Building Block in Medicinal Chemistry
}

\author{
Cristiane F. da Costa, Marcus Vinicius N. de Souza, ${ }^{*}$ Victor Facchinetti, and Claudia Regina B. Gomes \\ Farmanguinhos/Fiocruz, R. Sizenando Nabuco, 100, Manguinhos, 21041-250, Rio de Janeiro, RJ, Brazil \\ Email: mvndesouza@gmail.com (M. V. N. S.)
}

Abstract This work describes the synthesis of piperazine hydrochloride in multigram scale and high yields with promising industrial applications. This methodology is simple, fast, safe, low cost, and applicable to the synthesis of a wide variety of piperazine derivatives, being very useful in medicinal chemistry and other fields.

Keywords piperazine, medicinal chemistry, chloridrate, alkylation and acylation, green chemistry

\section{Introduction}

Piperazine (1,4-hexahydropyrazine) is a 6 -member heterocyclic ring, which contains two nitrogen atoms in its structure. This class of compounds was already known to be special in the early 1950's when piperazine was used as an anthelmintic drug. Nowadays, due to their potency and biological properties, piperazine and its derivatives still have a tremendous impact on the development of new drugs. ${ }^{[1]}$ The piperazine nucleus can be found in several classes of drugs and bioactive compounds with a wide range of biological activities, such as anti-malarial, anti-tuberculosis, antibacterial, antitumor, anti-inflammatory, anti-allergenic, anti-schizophrenia, anti-psychotic, anti-hypertensive, anti-tussive, anti-influenza, antiretroviral, among others. $^{[2-6]}$ Some examples of commercially available drugs bearing the piperazine moiety are shown in Figure 1.
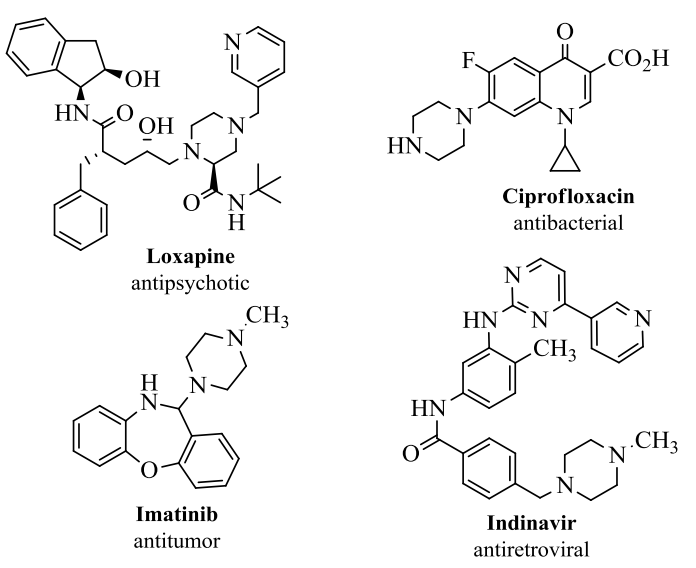

Figure 1 Piperazine scaffold: a remarkable tool in the generation of diverse pharmacological agents.

One major problem of piperazine chemistry is the di-alkylation or di-acylation of the piperazine core. ${ }^{[7-10]}$ This can be solved in an elegant way by using a procedure based on the synthesis of piperazine hydrochloride in situ, from one mole of piperazine and one mole of piperazine dihydrochloride, blocking one of the nitrogens and leading to easy synthesis of mono-alkylated or mono-acylated piperazine derivatives (Scheme 1). ${ }^{[11]}$ Therefore, the aim of this paper is to report an easy, clean and fast multigram scale synthesis to obtain
Scheme 1 Piperazine hydrochloride as an intermediate to mono-alkyl and mono-acyl piperazines

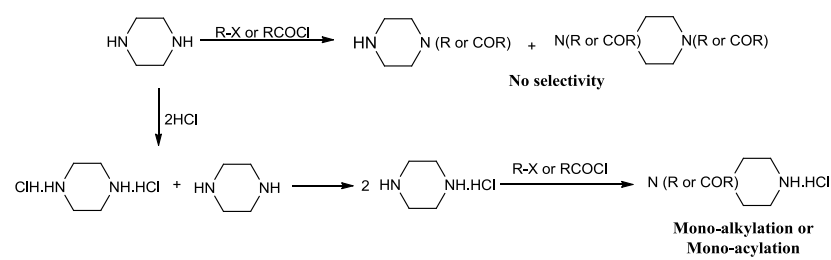

piperazine monochloridrate in large scale, which can be used as a building block to synthesize a wide variety of piperazine derivatives such as $\mathrm{N}$-methylpiperazine.

It is noteworthy that this procedure is very useful in medicinal chemistry and other fields with promising industrial applications.

\section{Results and Discussion}

Piperazine dihydrochloride was obtained by the addition of aqueous hydrochloric acid (37\%) to an ethanolic solution of piperazine under vigorous stirring until the equivalence point of the titration was reached and $\mathrm{pH}$ dropped to $1(160 \mathrm{~mL}$ of $\mathrm{HCl}$, Figure 2). The precipitate formed, a white solid, was filtered, washed with cool ethanol and dried under vacuum. It should be noted that this compound is usually synthesized by passing a stream of $\mathrm{HCl}(\mathrm{g})$ through the solution. ${ }^{[11]}$

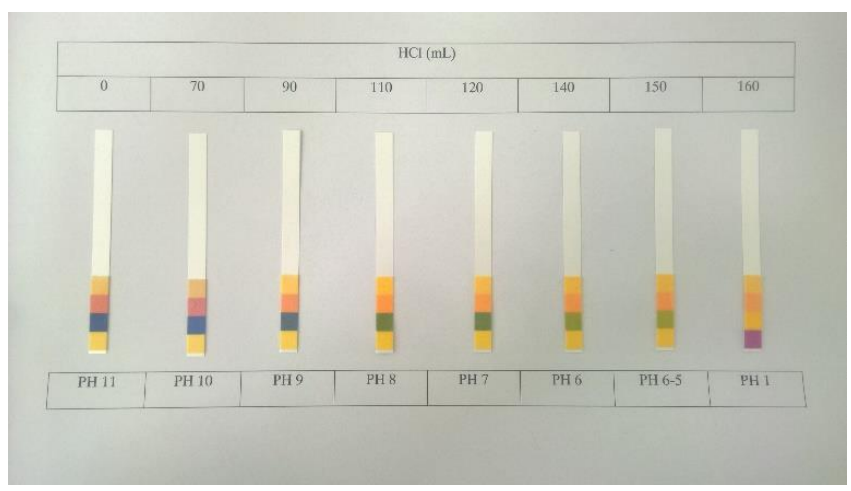

Figure $2 \mathrm{pH}$ variation observed with an universal $\mathrm{pH}$ indicator (Merck) during $\mathrm{HCl}$ addition. 
Scheme 2 Synthesis of piperazine dihydrochloride and piperazine hydrochloride

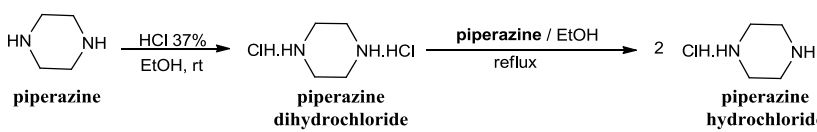

Piperazine hydrochloride was obtained by the reaction of piperazine dihydrochloride and piperazine in ethanol under reflux (Scheme 2). After cooling of the solution, the formation of white crystals was observed. The precipitate was filtered, washed with cold ethanol and allowed to dry under vacuum.

Both products and piperazine were analyzed by ${ }^{1} \mathrm{H}$ NMR and ${ }^{13} \mathrm{C}$ NMR $(400.00 \mathrm{MHz}$ and $100.00 \mathrm{MHz}$, respectively, in $\mathrm{D}_{2} \mathrm{O}$ with DSS as the internal standard). The ${ }^{1} \mathrm{H}$ NMR spectral data shows the deshielding of the hydrogens when comparing piperazine $(\mathrm{s}, \delta 2.74)$, to piperazine hydrochloride $(\mathrm{s}, \delta 3.11)$ and piperazine dihydrochloride $(\mathrm{s}, \delta 3.59)$, while the ${ }^{13} \mathrm{C}$ NMR displays the shielding of the carbons from piperazine to piperazine hydrochloride and piperazine dihydrochloride $(\delta$ $47.5,45.3$ and 43.1, respectively). The synthesized compounds were also submitted to thermal analyses carried out using thermogravimetric technique (TG) that provided useful data for thermal stability of the salts. Piperazine dihydrochloride showed an estimated mass loss of $13.90 \%$ within the temperature range $25-190^{\circ} \mathrm{C}$, which may be attributed to the loss of water. In the case of piperazine hydrochloride, an estimated mass loss of

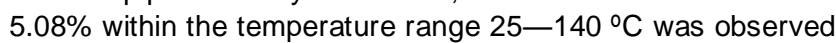
and may be attributed to the loss of volatile solvents.

Furthermore, in order to assess usability of the isolated piperazine hydrochloride in a chemical reaction, we synthesized 1-benzylpiperazine through in situ formation of piperazine hydrochloride (Scheme 3 , Eq. I) ${ }^{[10,11]}$ and direct synthesis (Scheme 3, Eq. II). It is noteworthy that direct synthesis from stocked piperazine hydrochloride displayed similar results when compared to the classic methodology, and the desired product was afforded with $85 \%$ and $81 \%$ yields, respectively. In both cases, excess piperazine was recovered as piperazine dihydrochloride $(97 \%$ yield) by filtration of the ethanolic solution. Ethanol was removed under reduced pressure and 1-benzylpiperazine hydrochloride retrieved from the crude oil after resolubilization in water and washing with ethyl acetate.

Scheme 3 Synthesis of benzylpiperazine from in situ classic formation of piperazine hydrochloride (I) and via direct synthesis from the previously obtained and stocked reagent

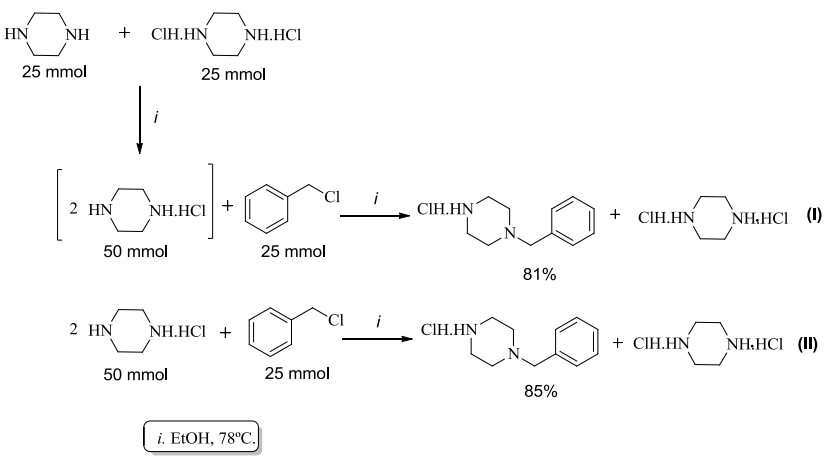

\section{Experimental}

\section{Instruments}

NMR spectra were analyzed using a $400 \mathrm{MHz}$ Bruker AC spectrometer with deuterated water as the solvent and DSS as the internal standard. Infrared spectra were obtained using a
Thermo Nicolet 6700 spectrometer and the Thermogravimetric Analysis were recorded from a Mettler Toledo TGA/SDTA 851e.

\section{General procedure}

Piperazine dihydrochloride: A $3 \mathrm{~L}$ round-bottomed flask equipped with a mechanical stirrer is charged with $86.14 \mathrm{~g} \mathrm{(1}$ mol) of piperazine and $250 \mathrm{~mL}$ of ethanol, in ambient temperature under stirring until total solubilization.

Hydrochloric acid $37 \%$ was then added slowly with an addition funnel, until $\mathrm{pH} 1$ was reached $(160 \mathrm{~mL})$. After the addition, the internal temperature did not exceed $50{ }^{\circ} \mathrm{C}$. The white precipitate obtained was filtered by suction on a glass Buchner funnel with sintered porous plate and washed with 100 $\mathrm{mL}$ of cool ethanol $\left(0^{\circ} \mathrm{C}\right)$, and then transferred to a to a tared $1 \mathrm{~L}$, round-bottomed flask and dried at $0.01 \mathrm{mbar}$ in high vacuum system for $16 \mathrm{~h}(154.01 \mathrm{~g} ; 97 \%)$ (Figure 3). ${ }^{1} \mathrm{H}$ NMR $\left(400 \mathrm{MHz}, \mathrm{D}_{2} \mathrm{O}\right) \delta: 3.61\left(8 \mathrm{H}, \mathrm{s}, \mathrm{CH}_{2}\right) .{ }^{13} \mathrm{C}$ NMR $\left(100 \mathrm{MHz}, \mathrm{D}_{2} \mathrm{O}\right)$ $\delta: 40.31\left(\mathrm{CH}_{2}\right)$. IR $v_{\text {max }}: 3471,2915,2780 \mathrm{~cm}^{-1}$.

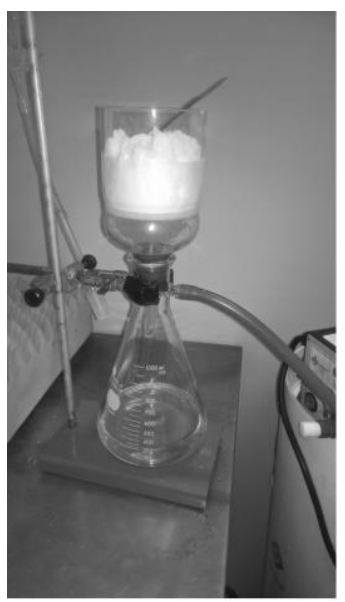

Figure 3 Piperazine dihydrochloride after filtration.

Piperazine hydrochloride: To a $1 \mathrm{~L}$, two-necked, roundbottomed flask equipped with a mechanical stirrer was added $79.57 \mathrm{~g}(0.5 \mathrm{~mol})$ of piperazine dihydrochloride and $500 \mathrm{~mL}$ of ethanol under stirring and reflux until total solubilization. Then, $43.07 \mathrm{~g}(0.5 \mathrm{~mol})$ piperazine was added slowly until total solubilization. The solution was cooled and the formation of a white precipitate was observed. The precipitate was filtered by suction on a glass Buchner funnel with sintered porous plate and washed with $200 \mathrm{~mL}$ of cool ethanol $\left(0{ }^{\circ} \mathrm{C}\right)$ (Figure 4), and then transferred to a tared $1 \mathrm{~L}$, round-bottomed flask and dried at $0.01 \mathrm{mbar}$ in high vacum system for $16 \mathrm{~h}(117.25 \mathrm{~g}$; $96 \%)$. ${ }^{1} \mathrm{H}$ NMR $\left(400 \mathrm{MHz}, \mathrm{D}_{2} \mathrm{O}\right) \delta: 3.13\left(8 \mathrm{H}, \mathrm{s}, \mathrm{CH}_{2}\right) \cdot{ }^{13} \mathrm{C}$ NMR $(100$ $\left.\mathrm{MHz}, \mathrm{D}_{2} \mathrm{O}\right) \delta: 42.53\left(\mathrm{CH}_{2}\right)$. IR $v_{\max }: 3415,3382,3243,2973$ $2834 \mathrm{~cm}^{-1}$.

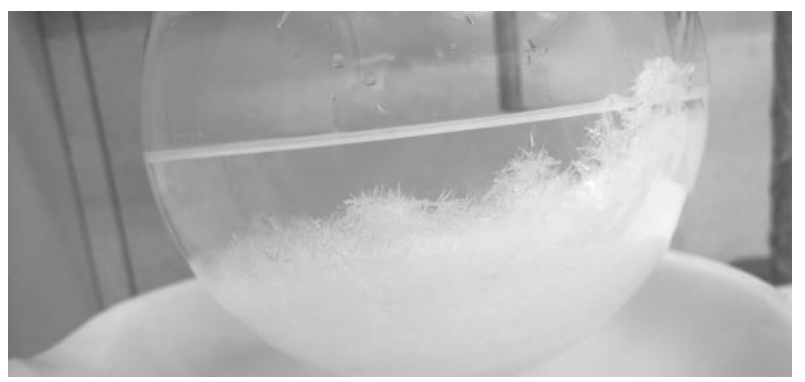

Figure 4 Precipitate formed after cooling.

Benzylpiperazine (through in situ formation of piperazine hydrochloride): Piperazine $(25 \mathrm{mmol})$, piperazine dihydrochloride $(25 \mathrm{mmol})$, and ethanol $(50 \mathrm{~mL})$ were added to a round-bottom flask $(100 \mathrm{~mL})$ under heavy stirring and reflux 
until the complete solubilization of the solid was seen (approx. 1 h). The reaction mixture is then transferred to another $100 \mathrm{~mL}$ round-bottom flask, containing $25 \mathrm{mmol}$ of the benzyl chloride, kept under reflux, and stirring for $2 \mathrm{~h}$. Piperazine dichloridrate was removed by filtration and the solvent was removed, resulting in the crude product, which was solubilized in water and purified by extraction with ethyl acetate $(3 \times 20 \mathrm{~mL})$. The desired benzylpiperazine was obtained as hydrochlorides after the evaporation of the aqueous layer.

Benzylpiperazine (from stocked piperazine hydrochloride): piperazine hydrochloride $(50 \mathrm{mmol}), 25 \mathrm{mmol}$ of the benzyl chloride, and ethanol $(50 \mathrm{~mL})$ were added to a round-bottom flask (100 $\mathrm{mL})$, and kept under reflux, and stirring for $2 \mathrm{~h}$. Piperazine dihydrochloride was removed by filtration and the solvent was removed, resulting in the crude product, which was solubilized in water and purified by extraction with ethyl acetate $(3 \times 20 \mathrm{~mL})$. The desired benzylpiperazine was obtained as hydrochlorides after the evaporation of the aqueous layer. ${ }^{1} \mathrm{H}$ NMR $\left(400 \mathrm{MHz}, \mathrm{D}_{2} \mathrm{O}\right) \delta: 7.48-7.39(\mathrm{~m}, 5 \mathrm{H}$, $\mathrm{Ph}), 3.80\left(\mathrm{~s}, 2 \mathrm{H}, \mathrm{CH}_{2}\right), 3.32-3.26(\mathrm{~m}, 4 \mathrm{H}$, piperazine), 2.91 (s, $4 \mathrm{H}$, piperazine). ${ }^{13} \mathrm{C}$ NMR (100 MHz, $\left.\mathrm{D}_{2} \mathrm{O}\right) \delta: 133.1(\mathrm{Ph}), 131.4$ (Ph), $131.2(\mathrm{Ph}), 64.2(\mathrm{CH} 2), 51.4$ (piperazine), 45.2 (piperazine).

\section{Conclusions}

We have developed a simple, fast, safe, and low cost multigram scale methodology for the synthesis of piperazine hydrochloride with promising industrial applications. It is important to mention that this product is stable and can be stocked, so large-scale pre-production of piperazine hydrochloride ends up being an interesting optimization to the original procedure, since the in situ equilibrium may take hours to be reached. Therefore, this procedure will be very useful to both synthetic and medicinal chemistry.

\section{Acknowledgement}

The authors would like to thank CAPES, CNPq and FIOCRUZ.

\section{Author Contributions}

Following are the details of the contributions made by each of the authors for the manuscript: All authors contributed directly to the design of the methodology, synthesis, interpretation of data and writing of this paper.

\section{Supporting Information}

Supporting information for this article is available on the WWW under www.genchemistry.org/EN/10.21127/yaoyigc20210004.

\section{Conflict of Interest}

The authors declare no conflict of interest.

Copyright (C) 2021 Cristiane França da Costa, Victor Facchinnetti, Claudia Regina Brandão Gomes, and Marcus Vinicius Nora de Souza. This article is an open access article distributed under the terms and conditions of the Creative Commons Attribution (CC BY) license (http://creativecommons.org/licenses/by/4.0/). The use, distribution or reproduction in other forums is permitted, provided the original author(s) or licensor are credited and that the original publication in this journal is cited, in accordance with accepted academic practice. No use, distribution or reproduction is permitted which does not comply with these terms.

\section{References}

[1] Shrestha, B.; Banerjee, J.; Yadav, P. K.; Gupta, A. K.; Khanal, H. Comparison of antihelminthic activity between bisaryl benzyl piperazine and benzimidazole linked piperazine derivatives. Int. J. Pharm. Sci. Res. 2016, 7, 1547-1555.

[2] Asif, M. Piperazine and Pyrazine containing molecules and their diverse pharmacological activities. Int. J. Adv. Sci. Res. 2015, 1, 5-11.

[3] Ashton, K.; Denti, M.; Norman, M. H.; St. Jean Jr., D. J. A general method for the facile synthesis of optically active 2-substituted piperazines via functionalized 2,5-diketopiperazines. Tetrahedron Lett. 2014, 55, 4501-4504.

[4] Sharma, P. C.; Jain, A.; Yar, M. S.; Pahwa, R.; Singh, J.; Goel. S. Synthesis and antibacterial evaluation of novel analogs of fluoroquinolones annulated with 6-substituted-2-aminobenzothiazoles. Arab. J. Chem. 2015, 8, 671-677.

[5] Popovic, D.; Nuss, P.; Vieta, E. Revisiting loxapine: a systematic review. Ann. Gen. Psychiatry 2015, 14-15, 1-8.

[6] Rathi, A.; Syed, R.; Shin, H. S.; Patel, R. V. Piperazine derivatives for therapeutic use: a patent review (2010-present). Expert Opin. Ther. Pat. 2016, 26, 777.

[7] Liu, J.; Fitzgerald, A. E.; Mani, N. S. Reductive amination by continuous-flow hydrogenation: direct and scalable synthesis of a benzylpiperazine. Synthesis 2012, 44, 2469-2473.

[8] Vu, C. B.; Peng, B.; Kumaravel, G.; Smits, G.; Jin, X.; Phadke, D.; Engber, T.; Huang, C.; Reilly, J.; Tam, S.; Grant, D.; Hetu, G.; Chen, L.; Zhang, J.; Petter, R. C. Piperazine Derivatives of [1,2,4]Triazolo[1,5-a][1,3,5]triazine as Potent and Selective Adenosine A2a Receptor Antagonists. J. Med. Chem. 2004, 47, 4291-4299.

[9] Moore, T. S.; Boyle, M.; Thorn. V. M. VIII. $-N$-substituted derivatives of piperazine and ethylenediamine. Part I. The preparation of $\mathrm{N}$-monosubstituted derivatives. J. Chem. Soc. 1929, 39-51.

[10] Baltzly, R.; Buck, J. S.; Lorz, E.; Schön, W. The Preparation of N-Mono-substituted and Unsymmetrically Disubstituted Piperazines. J. Am. Chem. Soc. 1944, 66, 263-266.

[11] Craig, J. C.; Young, R. J. 1-Benzylpiperazine. Org. Synth. 1962, 42, 19-20.

[12] Nery, A. C. S.; Gomes, C. R. B.; Pinheiro, A. C.; Facchinetti, V.; de Souza, M. V. N. Synthesis of benzylpiperazine derivatives containing the pyrazine moiety with potential activity against $M$. tuberculosis. Braz. J. Hea. Rev. 2020, 3, 15340-15354.

Received April 27, 2021

Accepted May 19, 2021 